\title{
Abnormal Platelet
}

National Cancer Institute

\section{Source}

National Cancer Institute. Abnormal Platelet. NCI Thesaurus. Code C37038.

A platelet characterized by a structural or functional abnormality. 